\title{
Mebendazole Selective Membrane Sensor and Its Application to Pharmaceutical Analysis
}

\author{
K. Girish Kumar, ${ }^{\dagger}$ Sareena John, Pearl Augustine, Remalakshmy Poduval, and \\ Beena SARASWATHYAMma
}

Department of Applied Chemistry, Cochin University of Science and Technology, Kochi-682 022, India

\begin{abstract}
A PVC membrane sensor for the selective determination of mebendazole (MBZ) was fabricated. The sensor is based on an ion association of MBZ with silicotungstic acid (STA) as ion pair and bis(2-ethylhexyl)phthalate (BEP) as the plasticizing agent in a PVC matrix. The sensor showed a linear response for MBZ for a concentration range $1.0 \times 10^{-6}-$ $5.0 \times 10^{-2} \mathrm{M}$ with a Nernstian slope of $55.8 \mathrm{mV} /$ decade (limit of detection $6.3 \times 10^{-7} \mathrm{M}$ ) in the pH range $4-7$. It has a fast response time of $<30 \mathrm{~s}$. The sensor showed a very good selectivity for MBZ with respect to a large number of ions. The direct determination of MBZ in pharmaceutical formulations gave results that compare well with the data obtained from the standard method.
\end{abstract}

(Received March 30, 2006; Accepted October 5, 2006; Published March 10, 2007)

\section{Introduction}

Mebendazole (MBZ) (5-benzoyl-2-benzimidazolylcarbamic acid methyl ester) $\left(\mathrm{C}_{16} \mathrm{H}_{13} \mathrm{~N}_{3} \mathrm{O}_{2}\right)$ is a broad spectrum anthelmintic drug producing high cure rates in infestations by ascaris, thread worms, hook worms and whip worms. ${ }^{1,2}$ MBZ causes slow immobilization and death of the worms by selectively and irreversibly blocking uptake of glucose and other nutrients in susceptible adult intestines where helminths dwell.

In recent years, potentiometric membrane sensors have been widely used in pharmaceutical analysis. ${ }^{3-5}$ Potentiometric methods using ion-selective electrodes have wide applications $^{6-11}$ because they are simple, economical and available over a wide range of different areas, and offer sufficient selectivity towards the drug in the presence of various pharmaceutical excipients. The low cost, ease of use and maintenance, the simplicity and speed of assay procedure and the reliability of the analytical information make the ionselective electrodes very attractive for the assay of pharmaceutical products.

The different analytical techniques available in the literature for the quantitative determination of MBZ include spectrophotometry, ${ }^{12}$ high performance liquid chromatography, ${ }^{13-18}$ liquid chromatography, ${ }^{19}$ thin layer chromatography ${ }^{20}$ and cathodic stripping voltammetry. ${ }^{21}$ Most of these methods are complicated and need sophisticated instruments.

In continuation to our work on drug analysis, ${ }^{22-25}$ an attempt has been made to develop an electrochemical sensor for the anthelmintic drug mebendazole.

The present work describes the fabrication, optimization and some possible applications of a novel MBZ PVC sensor based on the use of a mebendazole-silicotungstate ion pair complex as

$\dagger$ To whom correspondence should be addressed.

E-mail: giri@cusat.ac.in the electro active material and bis(2-ethylhexyl)phthalate (BEP) as plasticizer. The developed sensor displays high selectivity, long term stability, fast response and applicability over a wide range of $\mathrm{pH}$ and drug concentrations.

\section{Experimental}

\section{Reagents and chemicals}

All chemicals used in the study were of highest purity available and were used without further purification. Polyvinyl chloride powder (PVC) of high molecular weight was supplied by Merck. Dibutyl sebacate (DBS), bis(2-ethylhexyl)phthalate (BEP), bis(2-ethylhexyl)adipate (BEA), bis(2-ethylhexyl)sebacate (BES), di- $n$-butyl phthalate (DBP), phosphotungstic acid (PTA), molybdophosphoric acid (MPA) and silicotungstic acid (STA) were purchased from Lancaster and used as received. Tetrahydrofuran (THF) was obtained from s.d. fine chemicals and all of the metal salts used (all from Merck) were of the highest purity available. Aqueous solutions of the salts were prepared by dissolving the appropriate salt or diluting standard solutions as specified in doubly distilled water. Aqueous solutions of the drug were freshly prepared by accurate dilutions of a standard $10^{-1} \mathrm{M}$ stock drug solution using dilute nitric acid $(10 \% \mathrm{v} / \mathrm{v})$ as solvent. Pure-grade MBZ was obtained as a gift sample. Pharmaceutical formulations containing MBZ were obtained from local drug stores.

\section{Apparatus}

All potentiometric measurements were carried out at $25 \pm 1^{\circ} \mathrm{C}$ using a Systronics 335 digital ion meter. A saturated calomel electrode (SCE) was used as the external as well as the internal reference electrode. The electrochemical cell assembly may be represented as: saturated calomel electrode/internal filling solution $\left(1 \times 10^{-1} \mathrm{M} \mathrm{NaCl}\right.$ solution $+1 \times 10^{-3} \mathrm{M}$ drug solution)/PVC membrane/test solution $/ \mathrm{KCl}$ salt bridge//saturated calomel electrode. 


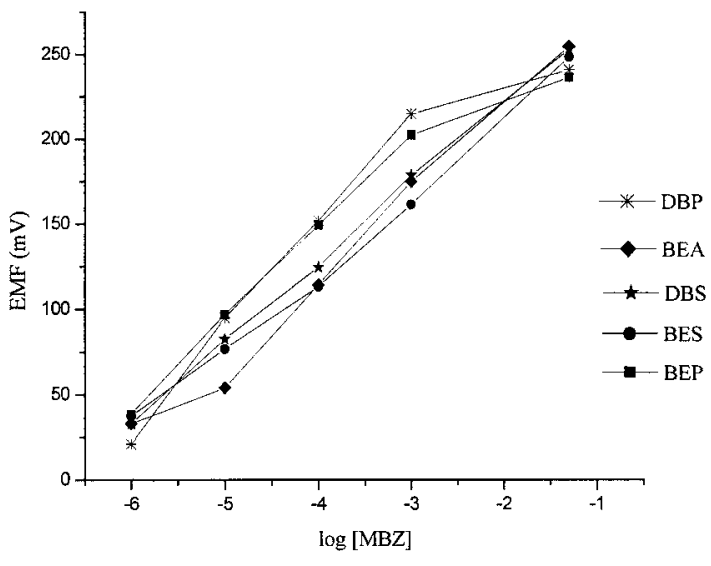

Fig. 1 Effect of plasticisers on the performance of the sensors.

\section{Preparation of MBZ-STA ion association}

The preparation of the ion association of MBZ was carried out by mixing about $25 \mathrm{~mL}$ of $0.01 \mathrm{M}$ solution of MBZ with $25 \mathrm{~mL}$ of $0.01 \mathrm{M}$ solution of STA under stirring. The obtained precipitate was filtered, washed thoroughly with distilled water, dried at room temperature and stored in a desiccator.

\section{Fabrication of the membrane electrode}

The ion associations were prepared using PTA, MPA and STA. Of the three, only the sensor prepared using MBZ-STA ion-association gave a linear plot. So this sensor was chosen for further studies. The preparation of the master membrane was done by the Craggs' procedure. ${ }^{26}$ The PVC membrane composition was $1.0 \%$ MBZ-STA ion-association complex, $64 \%$ BEP and $35 \%$ PVC (weight ratio) in $5-7 \mathrm{ml}$ of THF. The electrode body was filled with an inner filling solution containing $\mathrm{NaCl}\left(10^{-1} \mathrm{M}\right)$ and $\mathrm{MBZ}\left(10^{-3} \mathrm{M}\right)$. The finished electrode was preconditioned by soaking in a $1 \times 10^{-3} \mathrm{M} \mathrm{MBZ}$ solution for $24 \mathrm{~h}$ and stored in the same solution when not in use. The electrode was washed with distilled water before measurement. The inner filling solution was removed when not in use for a long time because the unstable drug solution may decompose after a long time. Moreover, a second set of readings was taken where the internal filling solution was changed daily. It was found that there was no change in either case.

\section{Procedure}

Standard solutions of $5 \times 10^{-2}-1 \times 10^{-6} \mathrm{M}$ were prepared by serial dilution of a $1 \times 10^{-1} \mathrm{M} \mathrm{MBZ}$ solution. The electrodes were placed into well-stirred $20 \mathrm{~mL}$ standard solutions in the order $1 \times 10^{-6}-5 \times 10^{-2} \mathrm{M}$ and stable potentials were recorded. The resulting calibration graph was used for subsequent determination of unknown MBZ.

\section{Determination of MBZ in pharmaceutical preparations}

Ten tablets were powdered and then dissolved in distilled water. Each solution was filtered through a piece of Whatman 41 filter paper, filtered into a volumetric flask and washed several times with water. The combined solution was quantitatively diluted to known volume. The presently developed sensor was directly immersed into $10 \mathrm{~mL}$ of sample solution 6 times and the potential was measured each time. The mean potential was used to evaluate the content of the drug in the tablet from the calibration graph (potential vs. log concentration).
Table 1 Effect of plasticizers on the performance of the sensors

\begin{tabular}{cc}
\hline Plasticizer used & Slope $/ \mathrm{mV}$ decade $^{-1}$ \\
\hline BEP & 55.8 \\
BES & 43.7 \\
DBS & 74.8 \\
BEA & 72.7 \\
DBP & 68.8 \\
\hline
\end{tabular}

Table 2 Effect of membrane composition of the sensor

\begin{tabular}{ccccc}
\hline \multirow{2}{*}{ Membrane } & \multicolumn{3}{c}{ Composition, \% (w/w) } & \multirow{2}{c}{$\begin{array}{c}\text { Slope/ } \\
\text { mV decade }^{-1}\end{array}$} \\
\cline { 2 - 3 } & Ion association & PVC & BEP & \\
\hline I & 1.0 & 35.0 & 64.0 & 55.8 \\
II & 1.2 & 46.0 & 52.8 & 61.5 \\
III & 1.8 & 63.5 & 34.7 & 53.9 \\
IV & 2.0 & 40.8 & 57.2 & 73.64 \\
\hline
\end{tabular}

\section{Results and Discussion}

\section{Performance characteristics of the sensor}

Five different plasticizers, viz. BEP, BES, DBS, BEA and DBP, were employed to study their effect on the electrochemical behavior of the membrane (Fig. 1). Generally, use of plasticizers improves certain characteristics of the membranes, and in some cases, the slopes get affected adversely. Here, the slopes in the case of the DBS, BEA and DBP are super-Nernstian and that of BES is sub-Nernstain. It was found that BEP gave a near Nernstian slope (Table 1). The construction of PVC-based membrane ISEs requires the use of a plasticizer, which mainly acts as a fluidizer allowing homogeneous dissolution and diffusional mobility of the ion pairs inside the membrane. The nature and/or the amount of the plasticizer must be properly controlled in order to minimize electrical asymmetry of the membrane and to limit fouling of the sensor. The variation observed in sensor response using different plasticizers may be attributed to different carrier mechanisms. ${ }^{27}$ BEP, being a low polarity plasticizer, provide more appropriate condition for the complexation of the ionophore. ${ }^{28,29}$ Different ratios of membrane composition were employed to evaluate their effects on the response characteristics of membrane sensor (Table 2). The results revealed that the best composition was ion association:PVC:plasticizer (BEP) at 1.0:35.0:64.0 wt\% (membrane I). The sensor exhibits a linear response over the range $1.0 \times 10^{-6}-5.0 \times 10^{-2} \mathrm{M}$ of $\mathrm{MBZ}$ with a slope of 55.8 $\mathrm{mV} /$ decade with an intercept $319.5 \pm 0.2$ (Fig. 2), and a lower detection limit of $6.3 \times 10^{-7} \mathrm{M}$. The life span of the sensor was found to be 6 weeks. Hence membrane I was used for subsequent studies.

\section{Effect of $p H$}

The influence of $\mathrm{pH}$ on the electrode potential response of MBZ membrane sensor was investigated using $1.0 \times 10^{-3} \mathrm{M}-$ drug solution over the $\mathrm{pH}$ range $1-11$ (Fig. 3). Adjustment of $\mathrm{pH}$ was carried out using hydrochloric acid or sodium hydroxide solution. From the $\mathrm{pH}$-potential profile, it was found that there was no change in the potential response within the $\mathrm{pH}$ range $4-7$ and hence this was chosen as the working $\mathrm{pH}$ range 


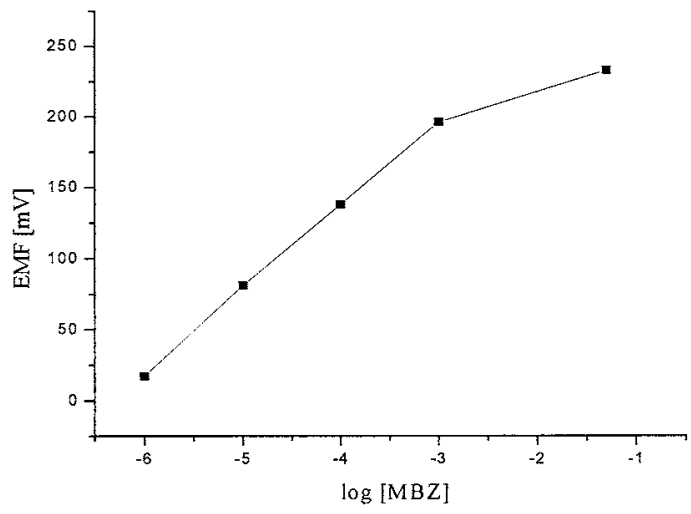

Fig. 2 Calibration graph for MBZ-selective membrane sensor at $25^{\circ} \mathrm{C}$

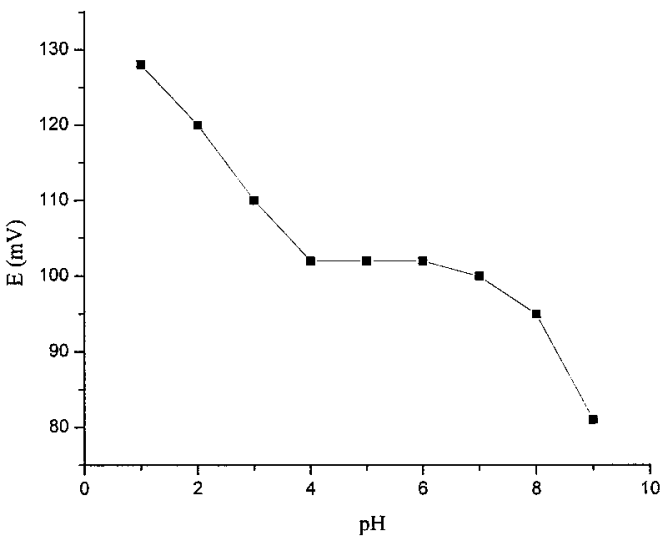

Fig. 3 Effect of $\mathrm{pH}$ of the test solution on the potential response of MBZ membrane sensor.

of the sensor. At higher $\mathrm{pH}$, the solution turned turbid due to the decomposition of the drug. This may be the reason for the decrease in potential. At lower $\mathrm{pH}$, the observed increase in potential may be due to the dissociation of the complex.

\section{Response time of the electrode}

The response time of the sensor is defined as the time required for the sensor to reach a stable potential within a value of \pm 1 $\mathrm{mV}$ of the final equilibrium value, after successive immersion of the sensor in different MBZ solutions. The response time for the presently developed MBZ membrane sensor was found to be less than $30 \mathrm{~s}$.

\section{Effect of foreign ions}

The interferences of various ions and uncharged species on selectivity of the sensor were investigated by the matched potential method (MPM). In the case that ISEs do not show Nernstian responses for both primary and interfering ions, MPM is recommended. ${ }^{30}$ Hence MPM was employed for the selectivity studies. The potentiometric selectivity coefficients are listed in Table 3. The results reveal that there were no significant interferences from any of the tested substances. The proposed sensor was fairly selective towards MBZ.

\section{Application}

The proposed membrane sensor was employed for the assay of MBZ content in tablets. The results were compared with
Table 3 Selectivity coefficient values of various interfering ions, $K^{\text {pot }}$

\begin{tabular}{ll}
\hline Interferent & $K^{\text {pot }}$ \\
\hline $\mathrm{Na}^{+}$ & $5.4 \times 10^{-3}$ \\
$\mathrm{~K}^{+}$ & $1.8 \times 10^{-3}$ \\
$\mathrm{NH}_{4}{ }^{+}$ & $6.2 \times 10^{-3}$ \\
$\mathrm{Cl}^{-}$ & $4.3 \times 10^{-3}$ \\
$\mathrm{Ca}^{2+}$ & $1.3 \times 10^{-4}$ \\
$\mathrm{~Pb}^{2+}$ & $4.4 \times 10^{-4}$ \\
$\mathrm{Co}^{2+}$ & $2.9 \times 10^{-3}$ \\
$\mathrm{Ni}^{2+}$ & $1.7 \times 10^{-4}$ \\
$\mathrm{Mg}^{2+}$ & $3.4 \times 10^{-2}$ \\
$\mathrm{Glycine}$ & $3.6 \times 10^{-3}$ \\
\hline
\end{tabular}

Table 4 Determination of MBZ in pharmaceutical formulations

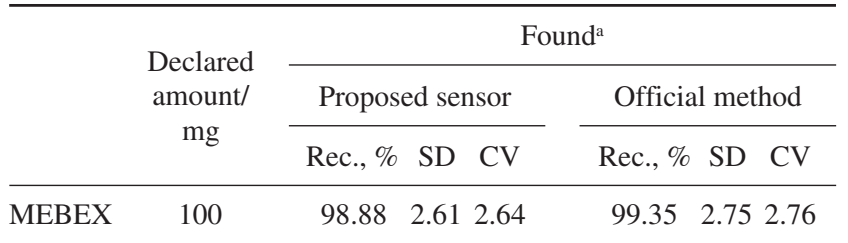

a. Average of 6 replicates.

those obtained by the European Phamacopoeia procedure (Table 4). ${ }^{31}$ The data given in the table clearly indicate a satisfactory agreement between the MBZ content determined by the proposed membrane sensor and the official method.

\section{Conclusion}

The results obtained in the present work demonstrate that the MBZ-STA ion pair as a new ionophore can be used in the development of a PVC-based MBZ ion-selective electrode. The developed sensor is found to have good characteristics in terms of slope, concentration range, detection limit, response time, $\mathrm{pH}$ range and shelf life. It is also found to be highly selective over a number of ions. Further, the developed sensor can be used in the determination of MBZ in pharmaceutical formulations.

\section{References}

1. M. R. Caira, T. G. Dekker, and W. Liebenberg, J. Chem. Crystallogr., 1998, 28(1), 11

2. A. A. Al-Badr and M. Tariq, "In Analytical Profiles of Drug Substances", 1987, Academic Press, New York, 291.

3. Z. Zhang and V. V. Cosofret, Selective Electrode Rev., 1990, $12(1), 35$.

4. V. V. Cosofret and R. P. Buck, "Pharmaceutical Application of Membrane Sensors", 1992, CRC Press, Boca Raton, 32.

5. V. V. Cosofret and R. P. Buck, Crit. Rev. Anal. Chem., 1993, 24(1), 1 .

6. S. S. M. Hassan, M. N. Abbas, and G. A. E. Mostafa, Talanta, 1996, 43, 797.

7. S. S. M. Hassan, M. N. Abbas, and G. A. E. Mostafa, Anal. Lett., 1998, 31, 777.

8. M. N. Abbas, G. A. E. Mostafa, and A. M. A. Homoda, Talanta, 2000, 53, 425 . 
9. M. N. Abbas, G. A. E. Mostafa, and A. M. A. Homoda, Talanta, 2001, 55, 647.

10. G. A. E. Mostafa, Anal. Sci., 2001, 17, 1043.

11. K. Vytras, J. Pharm. Biomed. Anal., 1989, 7, 789.

12. A. Kar, Analyst, 1985, 110(8), 1031.

13. J. G. Steenbaar, C. A. Hajee, and N. Haagsma, J. Chromatogr., 1993, 615(1), 186.

14. K. B. Alton, J. E. Patrick, and J. L. McGuire, J. Pharm. Sci., 1979, 68(7), 880 .

15. G. Karlaganis, G. J. Münst, and J. Bircher, J. High Resolut. Chromatogr., 2005, 2(3), 141.

16. E. M. A. Orsine, E. R. M. Kedor-Hackmann, and M. I. R. M. Santoro, Drug Dev. Ind. Pharm., 2000, 26(8), 879.

17. R. J. Allan, H. T. Goodman, and T. R. Watson, J. Chromatogr., 1980, 183(3), 311.

18. Z. Al-Kurdi, T. Al-Jallad, A. Badwan, and A. M. Y. Jaber, Talanta, 1999, 50, 1089.

19. C. A. Hajee and N. Haagsma, J. AOAC Int., 1996, 79(3), 645.

20. I. Vovk and B. Simonovska, J. AOAC Int., 2001, 84(4), 1264.
21. G. A. O'Keefe, W. W. Yakimets, A. J. Conesa, J. M. Pinilla, and L. Hernandez, Anal. Chim. Acta, 1996, 331(1), 111.

22. K. G. Kumar and R. Letha, J. Pharm. Biomed. Anal., 1997, 15,1725

23. K. G. Kumar, S. John, R. Poduval, and P. Augustine, The Chinese Pharmaceutical Journal, 2005, 57, 29.

24. K. G. Kumar, R. Poduval, S. John, and P. Augustine, Microchim. Acta, Published online on 11th May 2006.

25. K. G. Kumar, P. Augustine, R. Poduval, and S. John, Pharmazie, 2006, 61(4), 353.

26. A. Craggs, G. L. Moody, and J. D. R. Thomas, J. Chem. Educ., 1974, 51, 541.

27. S. S. M. Hassan, M. B. Saleh, A. Ahmed, A. Gaber, and N. A. A. Kream, Talanta, 2003, 59, 161.

28. D. Xu and T. Katsu, Anal. Chim. Acta, 2001, 443, 235.

29. N. K. Amini, A. Rafi, and I. Mohamnadpoor-Baltork, Anal. Lett., 2002, 35(11), 1795.

30. Y. Umezawa, K. Umezawa, and H. Sato, Pure Appl. Chem., 1995, 67(3), 507.

31. European Pharmacopoeia, 4th ed., 2002, France, 1531. 